\title{
Aktifasi Campuran Zeolit Alam Dan Flyash Batubara Menggunakan Microwave Sebagai Filter Udara Untuk Meningkatkan Akselerasi Mesin Sepeda Motor Bensin 4-Langkah
}

\author{
Bintoro Niko Renardy ${ }^{1}$, Herry Wardono ${ }^{1)}$, Dyan Susila1), \\ 1) Jurusan Teknik Mesin, Fakultas Teknik Universitas Lampung \\ Jln. Prof.Sumantri Brojonegoro No. 1 Gedung H FT Lt. 2 Bandar Lampung \\ Telp. (0721) 3555519, Fax. (0721) 704947 \\ email : nikobinto@gmail.com@gmail.com
}

\begin{abstract}
Combustion is a chemical process between fuel and oxygen utilizing heat. Ambient air contains a variety of gases such as nitrogen, oxygen, and other gases, causing incomplete combustion in the combustion chamber of a 4-stroke petrol engine. The use of artificial air filters with zeolite-flyash composition activated by microwave can adsorb the air that enters the combustion chamber. So that it can improve the quality of combustion. Zeolite is a mineral that is found in limestone mountainous areas, while coal flyash is material from coal combustion at PLTU. Both of these materials have the ability to adsorb molecular sized particles such as nitrogen, $C O$ and water vapor in the air, so the use of both materials is able to produce air with rich oxygen. The performance of the 4-stroke petrol engine is influenced by a decrease in fuel consumption, able to increase acceleration, and reduce exhaust emissions containing $\mathrm{CO}$ and $\mathrm{HC}$. To find out the effect of the use of activated zeolite-flyash filters on engine performance, an acceleration test of 0-60 $\mathrm{kph}$ was performed. Filter being activated by Microwave with $80 \%$ power, 6 minutes activation time, and density (variation in the number of pellets in the filter) 50\%,75\%, 100\%, and use the Z0: F100, Z25: F75, Z50: F50, Z75: F25, Z100: F0. The best filter is the composition of Z100:F0 with a compactness of 50\% able to increase acceleration by $7.17 \%$, followed by filter with composition of Z25:F75 with a compactness of $50 \%$ able to increase acceleration by $4,04 \%$.
\end{abstract}

Keywords : Zeolites, Coal Flyash, Petrol Engine, Air Filters.

\section{PENDAHULUAN}

Pembakaran merupakan reaksi kimia antara komponen - komponen bahan bakar (karbon dan hidrogen) dengan komponen udara (oksigen) yang berlangsung sangat cepat dan membutuhkan panas awal untuk menghasilkan panas yang jauh lebih besar sehingga menaikkan suhu dan tekanan gas pembakaran [6]. Oksigen di bumi paling umum yang jumlahnya mencapai $20.9 \%$ dari udara, dan hampir 79\% udara (tanpa adanya oksigen) merupakan nitrogen, dan sisanya merupakan elemen lainnya. Komposisi udara tersebut apabila masuk kedalam ruang bakar maka, akan berdampak pada pembakaran tidak sempurna sehingga, menurunkan kemampuan akselerasi mesin sepeda motor. Upaya yang dapat dilakukan untuk meningkatkan prestasi mesin adalah dengan menggunakan filter udara berbahan zeolit dan flyash batubara teraktivasi fisik menggunakan microwave. Fungsi dari filter udara ini ada sebagai penyaring udara yang masuk kedalam ruang bakar.

Zeolit merupakan jenis batuan yang memiliki kemampuan untuk menyerap (adsorben) gas $\mathrm{CO}, \mathrm{CO}_{2}, \mathrm{~N}_{2}$ dan NO. Zeolit merupakan mineral hasil tambang yang bersifat lunak dn mudah kering. warna dari zeolite adalah putih keabu-abuan. Ukuran Kristal zeolit kebanyakan tidak lebih dari 10-15 mikron [3] .Zeolit yang sudah teraktivasi fisik menyebabkan kristal yang didalam zeolit telah terdehidrasi, sehingga meningkatkan kemampuan adsorben yang selektif dan 
mempunyai efektivitas menyerap yang tinggi terhadap melekul yang polar (hidropilik) [1].

Flyash batubara adalah material yang memiliki ukuran butiran yang halus dan diperoleh dari hasil pembakaran batubara [5]. Pada pembakaran batubara dalam PLTU, terdapt limbah padat yaitu abu layang (flyash) dan abu dasar (bottommash). Komponen utama dari abu terbang batubara yang berasal dari pembangkit listrik adalah silika $0 \%-60 \%\left(\mathrm{SiO}_{2}\right)$, alumina 20\%-30\% $\left(\mathrm{Al}_{2} \mathrm{O}_{3}\right)$, dan besi oksida 4\%-10\% $\left(\mathrm{Fe}_{2} \mathrm{O}_{3}\right)$, sisanya adalah karbon, kalsium, magnesium, dan belerang [4]. Flyash memiliki kandungan silika dan alumina yang cukup tinggi dan karbon yang rendah flyash memiliki kemampuan untuk menyerap kandungan uap air, sehingga flyash dapat dijadikan sebagai adsorben untuk menangkap uap air yang ada di udara dan dapat disetarakan dengan zeolit.

Sebelum digunakan sebagai filter udara sepeda motor, zeolit dan flyash perlu diaktivasi fisik untuk meningkatkan kemampuan penyerapannya menggunakan microwave. Sehingga filter udara buatan ini dapat menghasilkan udara yang kaya akan oksigen kedalam ruang bakar. Peningkatan prestasi mesin motor bensin 4 langkah meliputi penurunan konsumsi bahan bakar, meningkatkan akselerasi, dan mereduksi gas buang yang mengandung gas gas berbahaya. Pengaruh penggunaan filter campuran zeolit dan flyash teraktivasi fisik terhadap prestasi mesin sepeda motor 100 cc mampu meningkatkan akselerasi sebesar 15,23\% dibandingkan tanpa menggunakan filter zeolitflyash. [2]

Tujuan dilakukannya penelitian ini adalah untuk mengetahui pengaruh filter zeolit-flyash teraktivasi fisik menggunakan microwave serta mengetahui pengaruh komposisi filter dan kerapatan pellet zeolit-flyash terhadap akselerasi sepeda motor mesin bensin 4 langkah.

\section{METODE PENELITIAN}

\section{Pembuatan Filter Zeolit-Flyash}

Bahan yang digunakan untuk membuat filter zeolite-flyash antara lain zeolit, flyash, perekat (tepung tapioka), dan air mineral. Alat yang digunakan yaitu tumbukan, ayakan dengan ukuran mesh 100, timbangan, wajan, kompor, ampia, cetakan, kawat streaming dan microwave. Pembuatan filter diawali dengan menghaluskan zeolit dan flyash secara terpisah, dengan cara ditumbuk lalu diayak dengan ukuran 100 mesh. Membuat adonan dan pencetakan pelet, komposisi adonan pelet yaitu 4\% (4 gram) perekat, 42\% (42 gram) air mineral, dan 54\% (54 gram) zeolite-flyash dengan dengan perbandingan Z100\%:F0\% Z75\%:F25\%, Z50\%:F50\%， Z25\%:F75\% Z0\%:F100\%, jumlah total yaitu 100 gram per adonan. Adonan yang telah jadi, kemudian diratakan menggunakan ampia hingga ketebalan $3 \mathrm{~mm}$ dan dicetak dengan diameter $10 \mathrm{~mm}$.

Melakukan pencetakan pelet yang sudah jadi, kemudian didiamkan selama 24 jam pada temperatur ruangan. Aktivasi pelet zeolit menggunakan microwave dengan daya yaitu $80 \%$, variasi waktu yaitu 6 menit. Setelah dilakukan aktivasi, pelet dikemas menggunakan kawat streaming. Pengemasan ini bertujuan agar memudahkan pemasangan pelet pada filter udara sepeda motor. Wadah kemasan pelet memiliki ukuran yang sama dengan filter udara sepeda motor yang digunakan dalam penelitian. Pada saat pengemasan dilakukan penghitungan jumlah pelet, dimana jumlah pelet saat wadah penuh yaitu sebanyak 72 butir. Pada penelitian ini menggunakan variasi jumlah pelet 100\% (72 butir), 75\% (54 butir), dan 50\% (36 butir).

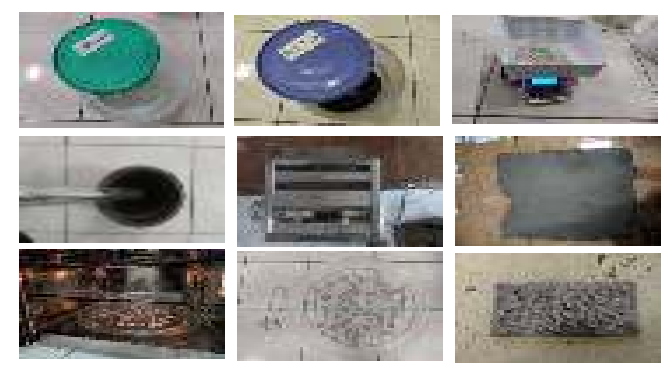

Gambar 1. Proses pembuatan filter zeolitflyash 


\section{Kendaraan Uji}

Penelitian ini menggunakan sepeda motor jenis Honda Karisma x 125 dengan kapasitas mesin $124,9 \mathrm{cc}$

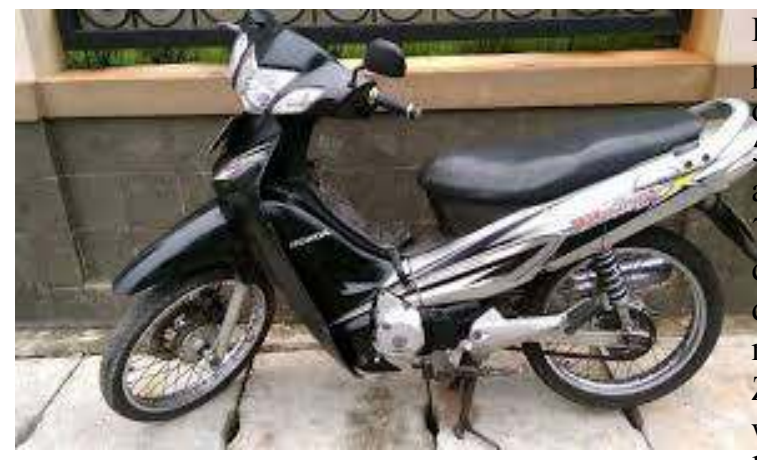

Gambar 2. Kendaraan Uji

Sebelum dilakukan pengujian kendaraan uji sudah dilakukan tune up berkala agar pada saat pengujian kendaraan dalam keadaan performa terbaik, sehingga memperoleh hasil pengujian yang valid.

\section{Prosedur Pengujian}

Pengujian akselerasi dilakukan dengan kecepatan $(0-60 \mathrm{Km} / \mathrm{J})$, pengujian akselerasi kendaraaan bertujuan untuk mengetahui berapa waktu yang dibutuhkan kendaraan dalam keadaan berhenti sampai berjalan mencapai kecepatan yang diinginkan $(0-60 \mathrm{Km} / \mathrm{J})$ dengan menggunakan filter buatan (filter zeolit-flyash batu bara). Jalur yang dibutuhkan untuk pengujian akselerasi sekitar 100-150 m. Persiapkan tangka bahan bakar buatan, bahan bakar, dan filter yang akan digunakan.

Mesin motor dipanaskan sebelum dilakukan pengujian agar diperoleh kondisi mesin yng sam pada saat pengujian. Pemasangan filter (filter standard an filter zeolit-flyash). Kemudian hidupkan kembali motor dan diposisikan pada jalur yang sudah disiapkan. Ketika gas ditarik (dari keadaan diam) hidupkan stoptwacth, setelah mencapai kecepatan yang diinginkan $(60 \mathrm{Km} / \mathrm{J})$ matikan stopwatch dan catat waktu yang tertulis pada stopwatch. Pada setiap pengujianya pengendara harus menarik gas secara teratur dan stabil. Langkah-langkah tersebut diulangi 3 kali setiap pengujian filter buatan dengan komposisi Z Z100\%:F0\% Z75\%:F25\%, Z50\%:F50\%, Z25\%:F75\% Z0\%:F100\% maupun tidak menggunakan filter buatan.

Pada pengujian didapatkan hasil bahwa pengguaan filter udara berbahan zeolit-flyash dengan komposisi Z100:F0 dan kerapatan filter $50 \%$ dapat meningkatkan kemampuan kselerasi sepeda motor dengan persentase $7,17 \%$, atau menempuh waktu rata-rata 6,82 letik $(0,53$ detik lebih cepat dibandingkan dengan menggunakan filter standar sepeda motor sebesar 7,35 detik. Pada komposisi filter Z25:F75 dengan kerapatan filter 50\% memiliki waktu tempuh rata-rata 7,05 detik atau 4,04\% lebih baik dibandingkan dengan filter standar.

\section{HASIL DAN PEMBAHASAN}

Pengujian waktu tempuh akselerasi dilakukan untuk mengetahui pengaruh komposisi zeolitflyash teraktivasi fisik menggunakan microwave, dan pengaruh kerapatan pelet zeolit-flyash terhadap waktu tempuh akselerasi (0-60 km/jam) sepeda motor bensin 4 langkah. Gambar 3 merupakan data pengujian waktu tempuh akselerasi yang telah dilakukan.

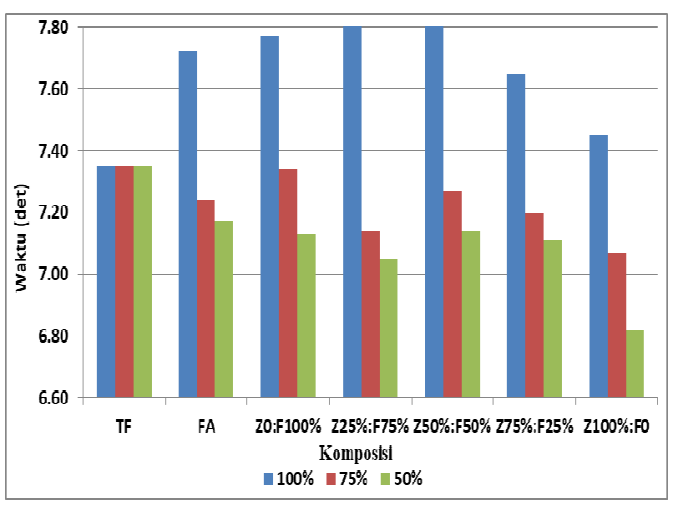

Gambar 3. Pengaruh kerapatan dan komposisi filter zeolit-flyash terhadap waktu tempuh akselerasi.

Pengguna filter udara berbahan zeolit-flyash terbuki mampu meningkatkan prestasi mesin dengan pengujian akselerasi. Filter dengan variasi komposisi Z100:F0 dengan kerapatan 
$50 \%$ menjadi filter dengan waktu tempuh akselerasi terbaik memperoleh catatan waktu 6,82 detik, hasil tersebut lebih cepat 0,53 detik dibandingkan dengan pengujian tanpa menggunakan filter (7,35 detik). Pada penggunaan filter komposisi Z25:F75 dapat memangkas waktu tempuh menjadi 7,05 detik $(4,04 \%)$ lebih cepat dibandingkan dengan filter standar.

Hal tersebut dikarenakan kerapatan (jumlah pellet dalam filter) yang renggang memiliki hambatan udara lebih kecil dibandingkan dengan susunan pellet rapat serta udara yang masuk kedalam ruang bakar kaya akan oksigen karena tersaring oleh filter zeolit-flyash.

Penggunaan filter zeolit-flyash terbukti mampu meningkatkan tenaga kendaraan, karena filter zeolit-flyash menyerap uap air, nitrogen dan zat-zat lain penghambat pembakarn. Sehingga udara yang masuk kedalam ruang bakar lebih banyak mengandung oksigen menjadikan pembakaran menjadi lebih sempurna.

\section{KESIMPULAN}

Komposisi filter zeolit-flyash telah teruji mampu meningkatkan kemampuan sepeda motor beakselerasi. Semakin sedikit jumlah pelet (kerapatan) di dalam filter zeolit-flaysh maka dapat meningkatkan akselerasi sepeda motor. Terbukti dengan komposisi Z100:F0 kerapatan 50\% mampu meningkatkan akselerasi sebesar 7,17\%, diikuti filter dengan komposisi Z25:F75 kerapatan 50\% meningkatkan akselerasi sebesar 4,04\%.

\section{DAFTAR PUSTAKA}

[1] Butland, T.D. 2008. Adsorption Removal OfTertiary Butyl Alcohol From Waste water By Zeolite. Thesis Of Worcester Polytechnic Institute Massahusetts.

[2] Ernadi, A. 2017. Pemanfaatan Campuran Zeolit Alam-Fly Ash Batu Bara Yang telah dikativasi Fisik Untuk Meningkatkan Prestasi Mesin Bensin 4-Langkah. Skripsi Jurusan Teknik Mesin-Universitas Lampung : Bandar Lampung,

[3] Ismiyati, S.D. 2015. Pengaruh Aktivasi
Terhadap Zeolit Alam Lampung Sebagai Adsorben GAS CO2 Dari Biogas. Prosiding Seminar Nasional Sains \& Teknologi VI. Jurnal Lembaga Penelitian dan Pengabdian Universitas Lampung. Bandar Lampung

[4] Rilham, Dimas. 2012. Pengaruh Aplikasi Fly Ash Bentuk Pelet Perekat Yang Diaktivasi Fisik Terhadap Prestasi Mesin Dan Emisi Gas Buang Sepeda Motor Bensin 4-Langkah. Skripsi Sarjana, Jurusan Teknik Mesin. Universitas Lampung. Bandar Lampung.

[5] Wardani, SRP. 2008. Pemanfaatan Limbah Batubara (Fly Ash) Untuk Stabilisasi Tanah Maupun Keperluan Teknik Sipil Lainnya Dalam Mengurangi Pencemaran Lingkungan. Dalam Pidato Guru Besar Jurusan Teknik Sipil Fakultas Teknik Universitas Diponegoro. Semarang.

[6] Wardono, H. 2004. Modul Pembelajaran Motor Bakar. Jurusan Teknik Mesin. Universitas Lampung. Bandar Lampung. 